\title{
Evaluating the State of the Journal: Past Successes and Future Plans
}

\author{
Jeremy N. Thomas \\ Center for Positive Sexuality (USA) \\ Idaho State University (USA) \\ jt@jeremythomas.org \\ D J Williams \\ Center for Positive Sexuality (USA) \\ Idaho State University (USA) \\ Emily E. Prior \\ Center for Positive Sexuality (USA)
}

\begin{abstract}
In this brief editorial, we evaluate the state of the Journal of Positive Sexuality and reflect on the journal's past successes and future plans. We consider the journal's relevance as illustrated through its unique character and approach, as well as through its impact as demonstrated according to various journal metrics. We highlight recent changes to our Submission Guidelines and conclude by discussing future plans for the journal.

\section{Introduction}

As the Journal of Positive Sexuality (JPS) begins its fifth year, we want to take this opportunity to reflect on the journal's past successes and future plans. Since its inception in 2015, JPS has established itself as one of the premier outlets for timely, relevant, and accessible research that intentionally bridges the often frustratingly-isolated contexts of the academic, professional, and community study and practice of sexuality. Unlike any other journal, JPS seeks to integrate knowledge and wisdom from these different contexts and create a product that can be commonly understood and broadly applied.

As such, JPS is unique in its appreciation of a wide range of perspectives, approaches, and topics. To borrow from the language of our recently updated Submission Guidelines, not only does JPS “encourage submissions from diverse epistemological perspectives," but we also "welcome a wide range of quantitative and qualitative methodological approaches, as well as theoretical and conceptual essays." Further, the topics appearing in JPS have firmly established it as one of the most diverse and cutting-edge sexuality journals in the world. From articles addressing some of the most important controversies of contemporary sexuality (e.g., debates about pornography), to articles investigating broad interdisciplinary concerns (e.g., sexuality and aging), to articles illuminating lesser-known sexual practices (e.g., recreational sounding with habanero juice)—JPS has explored sexuality from the mainstream to the deviant, and from the widely-known to the esoteric.
\end{abstract}




\section{Journal Metrics}

In its first four years, JPS has published 37 articles from 49 different authors. These authors have included students, professors, researchers, clinicians, and community members. They have represented a wide range of academic and professional disciplines, including anthropology, business, counseling, criminology, gender and women's studies, health and medicine, history, political science, psychology, sexology and sexuality studies, social work, and sociology. Many of these authors have also been members of sex-positive communities, groups, and organizations, including advocacy and service organizations as well as fraternal and interest groups related to LGBTQ, BDSM, kink, and vampire communities.

Since the publication of the journal's first issue in 2015, article views and downloads have steadily risen. In 2015, there were close to 5,000 article views and downloads. In 2016, this doubled to around 10,000. In 2017, this increased to nearly 35,000; and in 2018, this further increased to over 70,000. Some of the journal's most popular articles have included: “A Failure of Academic Quality Control: The Technology of Orgasm” by Hallie Lieberman and Eric Schatzberg (published in 2018 with over 46,000 total views and downloads); "No Pain, No Gain? Therapeutic and Relational Benefits of Subspace in BDSM Contexts” by Dulcinea Pitagora (published in 2017 with over 10,000 total views and downloads); and "Sexual Activity and Older Adults: Stigma, Overall Health, and Research” by Samantha Tupy, Matthew Schumann, and Xiaomeng Xu (published in 2015 with over 9,000 total views and downloads). Notably, journal readers have come from all over the world, including not just the United States and Canada, but also from the United Kingdom, Australia, Germany, and other countries in Europe, Asia, and South America.

Alongside these views and downloads, additional evidence of the journal's impact comes through multiple reports of articles being used as required reading in various college and university courses at both the undergraduate and graduate levels. Similarly, journal articles are being distributed by professional and community groups not only to their members but, in some case, also directly to clients in various professional and clinical contexts.

Finally, in terms of research impact, according to Google Scholar, JPS articles have been cited a total of 91 times. Some of the most cited articles include "Introducing a Multidisciplinary Framework of Positive Sexuality” by D J Williams, Jeremy N. Thomas, Emily E. Prior, and Wendy Walters (published in 2015 with 26 citations); "Sadomasochism without Sex? Exploring the Parallels between BDSM and Extreme Rituals” by Brad J. Sagarin, Ellen M. Lee, and Kathryn R. Klement (published in 2015 with 15 citations) and "Does BDSM Power Exchange among Women Reflect Casual Leisure? An Exploratory Qualitative Study” by Emily E. Prior and D J Williams (published in 2015 with 13 citations).

\section{Changes to Submission Guidelines}

Beginning this year, some adjustments have been made to our submission guidelines. In addition to minor clarifications regarding our style expectations and review processes, we are now specifying that while JPS has a preference for shorter manuscripts (2,000-3,000 words), we 
are also considering longer manuscripts up to 10,000 words. For all manuscripts, we are now asking authors to include a brief abstract (fewer than 100 words).

Our main intent here is to continue our emphasis on concise, accessible articles that appeal to as broad an audience as possible. At the same time, we want to allow for more traditional manuscripts, especially those that seek to bridge the academic, professional, and community study and practice of sexuality. We want JPS to become a leading destination for innovative and boundary-pushing scholarship, and we hope that our readers will continue to send us their best work.

\section{Looking to the Future}

As we move forward, we plan on publishing a minimum of two issues per year, typically appearing in March and September, with additional issues possible should the number of submissions allow. In general, we prefer to mirror the brief character of our articles by likewise producing concise and easily-readable issues of three to six articles each. We note that as an entirely online and open-access periodical, JPS maintains a complete archive of all past articles.

In the near future, we are also looking to further increase the indexing and database availability of JPS. Beginning in 2018, the journal is now listed on Ulrichsweb (ulrichsweb.serialssolutions.com), and this is the first step in JPS being listed in other periodical databases such as ProQuest and JSTOR. With such increased listings, JPS will be more readily identifiable and available not only to institutional, public, and private libraries, but also to corporate and government entities.

In conclusion, we want to thank our excellent Editorial Board for the time and energy that they have given over the last few years to establishing, developing, and strengthening the journal. On behalf of all of them, we are optimistic that we will see continued growth in the impact, readership, and scope of the Journal of Positive Sexuality.

\section{References}

Lieberman, H., \& Schatzberg, E. (2018). A failure of academic quality control: The technology of orgasm. Journal of Positive Sexuality, 4(2), 2447.

Pitagora, D. (2017). No pain, no gain? Therapeutic and relational benefits of subspace in BDSM contexts. Journal of Positive Sexuality, 3(3), 4454.

Prior, E. E., \& Williams, D. J. (2015). Does BDSM power exchange among women reflect casual leisure? An exploratory qualitative study. Journal of Positive Sexuality, 1(1), 12-15.
Sagarin, B. J., Lee, E. M., \& Klement, K. R. (2015). Sadomasochism without sex? Exploring the parallels between BDSM and extreme rituals. Journal of Positive Sexuality, 1(3), 3236.

Tupy, S., Schumann M., and Xu X. (2015). Sexual activity and older adults: Stigma, overall health, and research. Journal of Positive Sexuality, 1(3), 70-75.

Williams, D. J., Thomas, J. N., Prior, E. E., \& Walters, W. (2015). Introducing a multidisciplinary framework of positive sexuality. Journal of Positive Sexuality, 1(1), 611. 